\title{
PENGUJIAN STABILITAS SEDIAAN LUKA BAKAR BERBAHAN BAKU AKTIF KITOSAN/EKSTRAK PEGAGAN(CENTELLA ASIATICA)
}

\section{EVALUATION OF STABILITY OF WOUND HEALING FORMULA WITH ACTIVE SUBSTANCES OF CHITOSAN/CENTELLA ASIATICA EXTRACT}

\section{Eriawan Rismana, Idah Rosidah, Olivia Bunga, Prasetyawan Yunianto, dan Erna}

\author{
Pusat Teknologi Farmasi dan Medika \\ Badan Pengkajian dan Penerapan Teknologi \\ LAPTIAB Gedung 611 - Kawasan PUSPIPTEK - Serpong - Tangerang Selatan \\ Email: eriawan.rismana@bppt.go.id
}

Diterima: 22 Februari 2015, Revisi: 06 Maret 2015, Disetujui: 28 Maret 2015

\begin{abstract}
ABSTRAK
Telah dilakukan pengujian stabilitas sediaan luka bakar mengandung bahan aktif kitosan dan ekstrak pegagan (Centella asiatica) yakni stabilitas sifatfisika, kimia dan mikrobiologi. Pengujian stabilitas sifat fisika terdiri dari pengamatan organoleptik seperti parameter bentuk gel, bau, warna, homogenitas dan berat sediaan. Sedangkan Pengujian stabilitas kimia dilakukan terhadap parameter $\mathrm{pH}$ dan profil kromatogram KCKT. Adapun stabilitas biologi dilakukan terhadap parameter cemaran mikroba dan kapang-khamir. Hasil pengujian menunjukkan bahwa sediaan luka bakar yang dibuat mempunyai stabilitas fisika, kimia dan biologi yang baik selama penyimpanan 24 minggu pada suhu ruang dan 12 minggu pada suhu $40{ }^{\circ} \mathrm{C} / 75 \% \mathrm{RH}$.
\end{abstract}

Kata kunci: Sediaan luka bakar, kitosan, ekstrak pegagan, pengujian, stabilitas

\section{ABSTRACT}

The evaluation of wound-healing formula stability with active substance chitosan/Centella asiatica extract has been examined. The stability test was evaluated including physical, chemical and microbiology properties. The stability of physical property was observed by organoleptic parameters such as shape of gel, color, odor, homogeneity and weight of samples, while the stability of chemical property was studied by determination of $\mathrm{pH}$ and HPLC chromatogram profile. Meanwhile the stability of microbiology property was determined by contents by microbe and fungi contaminant. The results of evaluation showed that the wound-healing formula had a good stability for all properties after storage at room temperature for 24 weeks and 40 ${ }^{o} \mathrm{C} / 75 \%$ RH for 12 weeks.
Keywords: Wound-healing formula, chitosan, Centella asiatica extract, evaluation, stability

\section{PENDAHULUAN}

Pengujian stabilitas terhadap produk komersial berupa obat, kosmetik, olahan makanan dan minuman merupakan salah satu pengujian yang harus dilakukan oleh industri produsen atau laboratorium penguji sebelum produk diproduksi dan dipasarkan. Umumnya pengujian stabilitas merujuk pada prosedur dan standar kualitas yang dikeluarkan oleh Badan Pengawas Obat dan Makanan (BPOM) dan Kementerian Kesehatan seperti tercantum dalam Farmakope Indonesia, Farmakope Herbal Indonesia, PerKaBPOM, dan Permenkes terkait $^{(1-4)}$.

Stabilitas didefinisikan sebagai kemampuan suatu produk untuk bertahan kualitasnya sesuai spesifikasi kualitas yang ditetapkan sepanjang periode waktu penggunaan dan atau penyimpanan. Pengujian stabilitas dilakukan untuk menjamin identitas, kekuatan, kualitas dan kemurnian produk yang telah diluluskan dan beredar di pasaran, sehingga aman untuk digunakan oleh konsumen. Berdasarkan hasil pengujian tersebut dapat diketahui pengaruh faktor lingkungan seperti suhu dan kelembaban terhadap 
parameter-parameter stabilitas produk seperti kandungan zat aktif, $\mathrm{pH}$, berat jenis, bau, warna, viskositas, rasa, kandungan mikroba dan lainnya sehingga dapat ditetapkan tanggal kedaluwarsa yang sebenarnya. Untuk sediaan obat dan kosmetik stabilitas lebih ditujukan pada kemampuan produk tersebut untuk mempertahankan sifat dan karakteristik khasiat agar sama dengan yang dimilikinya pada saat dibuat hingga batasan yang ditetapkan sepanjang periode penyimpanan dan penggunaan (shelf-life) ${ }^{(1,5,6)}$.

Umumnya uji stabilitas dilakukan terhadap produk baru atau bila ada perubahan pada proses produksi (menggunakan alat baru atau metode pengolahan), perubahan formula, perubahan bahan awal dan bahan pengemas. Sedangkan pada produk yang sudah tervalidasi namun tidak mengalami perubahan selama proses produksi maka dilakukan post marketing stability test. Berdasarkan lama pengujian, uji stabilitas dibagi menjadi dua yakni uji stabilitas jangka pendek (dipercepat) dan jangka panjang (real time study). Uji stabilitas jangka pendek dilakukan selama 6 bulan dengan kondisi ekstrim (suhu $40 \pm 20{ }^{\circ} \mathrm{C}$ dan RH $75 \pm 5 \%$ ), sedangkan uji stabilitas jangka panjang dilakukan sampai dengan waktu kadaluwarsa produk seperti yang tertera pada kemasan. Jenis pengujian stabilitas untuk sediaan obat dan kosmetik adalah meliputi stabilitas terapi/khasiat, stabilitas fisika, stabilitas kimia, stabilitas mikrobiologi, dan stabilitas teratologi ${ }^{(1,5,6)}$.

Salah satu formula sediaan baru yang dibuat dan diteliti oleh Pusat Teknologi Farmasi dan Medika - BPPT adalah sediaan luka bakar berbahan aktif kitosan dan ekstrak pegagan. Penggunaan ekstrak pegagan dan kitosan merupakan terobosan baru penggunaan bahan alami sebagai bahan aktif pada sediaan luka bakar. Herba Pegagan (Centella Asiatica L.) Urban merupakan salah satu tanaman famili umbellifearae yang telah banyak diteliti dan berkhasiat sebagai obat luka bakar serta dapat menstimulasi kolagen pada jaringan kulit ${ }^{[7-10]}$. Hasil penelitian menunjukkan bahwa senyawa yang berperan untuk pengobatan luka bakar pada herba pegagan adalah asiaticoside, sehingga senyawa asiaticoside inilah yang dijadikan penanda dan diharapkan kadarnya setinggi mungkin dalam fraksi ekstrak yang akan digunakan saat formulasi ${ }^{(9-12)}$. Selain itu ekstrak pegagan mempunyai efek sebagai antinosiseptik dan antiinflamasi yang dapat mensinergiskan pada pengobatan luka bakar ${ }^{[11]}$. Komponen bioaktif triterpenoid dalam pegagan yaitu asiaticoside, asiatic acid, madecassocide dan madeccasic acid mempunyai kemampuan sebagai obat luka bakar, antinosiseptik dan antiinflamasi ${ }^{(11-16)}$.

Kitosan merupakan polimer alami yang diperoleh dari deasetilasi kitin. Kitosan merupakan polimer yang aman dan mempunyai sifat tidak beracun, biocompatible dan biodegradable ${ }^{(17)}$. Di bidang farmasi, kitosan dapat digunakan sebagai bahan pelapis, pembentuk film, mukoadhesif, pengikat, dan peningkat viskositas. Kitosan dapat digunakan sebagai wound-healing karena sifatnya yang dapat menghambat fibroplasia dan meningkatkan pertumbuhan jaringan. Oleh karena itu kitosan dapat digunakan sebagai bahan aktif dan bahan pembawa polimer biodegradable pada bentuk sediaan topikal

Hasil uji khasiat yang telah dilakukan menunjukkan bahwa sediaan luka bakar mengandung kitosan dan esktrak pegagan dapat menyembuhkan luka bakar yang baik [18]. Merujuk pada Farmakope Indonesia danPerKaBPOM ${ }^{(1-4,19)}$ maka suatu sediaan sebelum diproduksi dan dipasarkan harus dilakukan pengujian stabilitas yang meliputi sifatfisika, kimia, dan biologi.Hal yang sama juga dilaporkan pada pengujian stabilitas sediaan anti acne berbahan baku aktif berbahan baku aktif nanopartikel kitosan/ekstrak manggis - pegagan ${ }^{(20)}$ dan sediaan gel berkhasiat sebagai vasodilator dengan bahan aktif perasan herba seledri ${ }^{(21)}$. 
Dalam penelitian ini telah dilakukan uji stabilitas terhadap formula baru suatu sediaan luka bakar dengan bahan aktif kitosan - ekstrak pegagan. Penelitian ini bertujuan untuk mendapatkan data - data stabilitas sediaan luka bakar meliputi parameter bentuk gel, warna, bau, homogenitas, konsistensi berat sediaan, $\mathrm{pH}$, profil KCKT, kandungan senyawa aktif/markerdan cemaran mikrobiologi. Sedangkan manfaat penelitian ini adalah untuk menjamin khasiat dan keamanan sediaan sebelum diproduksi pada skala besar/industri dan diedarkan serta untuk memprediksi waktu kadaluwarsa produk.

\section{BAHAN DAN METODE}

\section{Bahan}

Metolose ${ }^{\circledR} \quad$ (ShinEtsu, Jepang), polietilen glikol (Bratachem, Indonesia), Trietanolamin (Bratachem, Indonesia), Nipagin (Bratachem, Indonesia), Nipasol (Bratachem, Indonesia), pewangi (Bratachem, Indonesia), air, kitosan (grade farmasi, Vitalhouse, Indonesia), asam laktat teknis (Bratachem, Indonesia) dan ekstrak pegagan (PTFM, BPPT).

\section{Peralatan}

Neraca analitik (Precisa), $\mathrm{pH}$ meter (Thermo), alat-alat gelas, kromatografi cair kinerja tinggi (KCKT) (Waters 2487), spektrofotometer (Genesys 10 UV), climatic chamber (WTB Binder).

\section{Metode}

\section{Pembuatan Sediaan Woundhealing}

Basis sediaan gel dibuat dengan mencampurkan ekstrak pegagan dan kitosan (yang dilarutkan dalam asam asam laktat), metolose, propilenglikol, trietanolamin, nipagin, nipasol, pewangi, dan air. Sediaan gel yang diuji mengandung bahan aktif ekstrak pegagan dankitosan masing masing adalah $0,5 \%$, dan $1,5 \%$. Komposisi bahan secara lengkap ditunjukkan pada Tabel $1^{[18]}$.

Tabel 1. Komposisi sediaan luka bakar mengandung kitosan dan ekstrak pegagan

\begin{tabular}{lr}
\hline \multicolumn{1}{c}{ Bahan } & Komposisi \\
\hline Ekstrak pegagan & $0,5 \%$ \\
Kitosan & $1,5 \%$ \\
Asam laktat 4\% & $20 \%$ \\
Metolose & $3 \%$ \\
Propilenglikol & $5 \%$ \\
Trietanoolamine & $1 \%$ \\
Nipagin & $0,2 \%$ \\
Nipasol & $0,02 \%$ \\
Pewangi & Qs \\
Air & Add 100 \\
\hline
\end{tabular}

\section{Penyiapan sampel dan kondisi pengujian} stabilitas

Sampel uji disiapkan dan dikemas pada tube dengan berat sekitar 7 gram. Pada setiap sampel kemudian dilakukan pelabelan dengan identitas kondisi penyimpanan, nomor batch dan waktu sampling. Untuk uji stabilitas dipercepat sampel dimasukkan ke dalam climatic chamber dengan kondisi suhu $40{ }^{\circ} \mathrm{C} / \mathrm{RH} 75$ $\%$ selama 3 bulan. Pengambilan sampel uji dilakukan setiap 2 minggu sekali yaitu minggu ke-0, 2, 4, 6, 8, 10, dan 12 . Sedangkan untuk uji stabilitas diperpanjang sampel disimpan pada suhu kamar selama 6 bulan dan pengambilan sampel dilakukan pada minggu ke-0, 2, 4, 6, 8, 10, 12, 16, 20, dan 24. Pengujian dilakukan terhadap sampel secara duplo ${ }^{(1) .}$

\section{Pengujian stabilitas fisika dan kimia}

Pengujian stabilitas fisika sediaan dilakukan dengan mengamati bentuk gel, warna, bau, homogenitas dan mengukur konsistensi berat. Pengujian stabilitas kimia dilakukan dengan mengamati $\mathrm{pH}$ dan profil kromatogram hasil análisis KCKT. Penentuan $\mathrm{pH}$ sampel dilakukan setelah $\mathrm{pH}$ meter dikalibrasi terhadap larutan dapar $\mathrm{pH}$ 4 dan $\mathrm{pH} 7^{(3)}$. Sedangkan kondisi KCKT 
dilakukan sebagai berikut: sejumlah tertentu sampel ditimbang, kemudian dilarutkan dalam metanol hingga diperoleh konsentrasi yang ditentukan. Sejumlah 20 $\mu \mathrm{L}$ larutan sampel disuntikan dalam KCKT Waters 2487 menggunakan kolom MetaChem 046x250 mm C8, fase gerak asetonitril: air (27:73), kecepatan 1 $\mathrm{mL} / \mathrm{menit}$, dan detektor UV panjang gelombang $206 \mathrm{~nm}^{(22)}$.

\section{Penentuan stabilitas biologi}

Dilakukan dengan mengamati jumlah cemaran mikroba dan kapang - khamir. Prosedur uji dilakukan sebagai berikut :

Penentuan cemaran mikroba angka lempeng total (ALT)

Disiapkan 5 buah tabung yang telah diisi dengan $9 \mathrm{~mL}$ pengencer Pepton Dilution Fluid (PDF). Dari hasil homogenisasi pada penyiapan contoh dipipet pengenceran $10^{-1}$ sebanyak $1 \mathrm{~mL}$ kedalam tabung yang berisi pengencer PDF pertama hingga diperoleh pengenceran $10^{-2}$ dan dikocok hingga homogen, selanjutnya untuk tabung-tabung berikutnya dibuat pengenceran hingga $10^{-6}$. Dari setiap pengenceran dipipet $1 \mathrm{~mL}$ ke dalam cawan petri dan dibuat duplo. Ke dalam tiap cawan petri dituangkan $15-20 \mathrm{~mL}$ media PDA (Potato Dextrosa Agar) suhu $45{ }^{\circ} \mathrm{C}$ dan segera cawan petri digoyang sehingga suspensi tersebar merata. Dibuat kontrol untuk menguji sterilisasi media dan pengencer. Setelah media memadat, cawan petri diinkubasi pada suhu $35-37{ }^{\circ} \mathrm{C}$ selama 24-48 jam dan kemudian dihitung jumlah koloni yang tumbuh ${ }^{[1,4]}$.

\section{Penentuan cemaran mikroba angka kapang - khamir (AKK)}

Disiapkan 3 buah tabung yang telah diisi dengan $9 \mathrm{ml}$ Air Suling Agar (ASA). Dari hasil homogenisasi pada penyiapan contoh dipipet $1 \mathrm{~mL}$ pengenceran $10^{-1} \mathrm{ke}$ dalam tabung ASA pertama hingga diperoleh pengenceran $10^{-2}$, dan selanjutnya dibuat hingga pengenceran hingga $10^{-4}$. Dari masing-masing pengenceran dipipet $0,5 \mathrm{~mL}$, dituangkan pada permukaan media dalam cawan petri yang telah berisi $15-20$ $\mathrm{mL}$ media Potato Dextrosa Agar (PDA), segera digoyangkan sambil diputar agar suspensi tersebar merata dan dibuat duplo. Untuk mengetahui sterilitas media dan pengencer, dilakukan uji blanko.Seluruh cawan petri diinkubasi pada suhu $20-25{ }^{\circ} \mathrm{C}$ selama 5-7 hari. Sesudah 5-7 hari inkubasi, dicatat jumlah koloni jamur yang tumbuh $(1,4)$

\section{HASIL DAN PEMBAHASAN}

Hasil pengujian stabilitas fisika terhadap bentuk gel, warna, bau dan homogenitas sampel sediaan luka bakar secara duplo pada penyimpanan suhu kamar dan suhu $40{ }^{\circ} \mathrm{C}$ RH $75 \%$ ditunjukkan pada Tabel 2 dan 3. Hasil uji pengamatan bentuk gel pada suhu kamar menunjukan bahwa sampai minggu ke 12 ditemukan tidak ada perubahan bentuk gel, tetapi diantara minggu ke 16 - 24 terjadi perubahan bentuk gel menjadi sedikit lebih encer. Sedangkan pada suhu $40{ }^{\circ} \mathrm{C}$ RH $75 \%$ bentuk gel stabil hingga pengamatan minggu ke 12 . Bentuk gel yang lebih encer diduga terjadi interaksi atau penguraian bahan metolose pada kondisi $\mathrm{pH}$ asam sediaan.

Hasil uji pengamatan warna sediaan pada suhu kamar menunjukkan warna kuning muda kehijauan yang stabil hingga minggu ke 8 dan berubah menjadi coklat muda kehijauan hingga kuning coklat pada pengamatan minggu ke $10-24$. Sedangkan pada suhu $40{ }^{\circ} \mathrm{C}$ RH $75 \%$ penampakan warna kuning muda kehijauan gel stabil hingga pengamatan minggu ke 6 dan mulai berubah menjadi hijau kecoklatan hingga coklat muda pada minggu ke $8-12$. Hal ini diduga kemungkinan karena terjadi proses oksidasi selama penyimpanan.

Hasil uji pengamatan homogenitas sediaan pada suhu kamar dan suhu $40{ }^{\circ} \mathrm{C}$ 
RH $75 \%$ menunjukkan stabilitas yang baik pada masing - masing pengamatan hingga minggu ke 12 dan 24. Pengujian stabilitas bau sediaan pada suhu kamar menunjukkan bahwa hingga minggu ke 12 keharuman sediaan relatif stabil dan mulai menurun intensitasnya mulai minggu ke $16-24$. Sedangkan pada suhu $40{ }^{\circ} \mathrm{C}$ RH $75 \%$ intensitas keharuman stabil hingga minggu ke 4 dan mulai menurun pada minggu ke 6 - 12. Hal ini kemungkinan besar disebabkan karena pewangi yang digunakan mengalami proses penguapan atau degradasi selama waktu penyimpanan.

Hasil uji stabilitas fisika terhadap parameter berat sampel sediaan luka bakar yang telah disimpan selama 24 minggu pada suhu kamar dan 12 minggu pada kondisi $40{ }^{\circ} \mathrm{C}$ RH $75 \%$ ditunjukkan pada Gambar 1. Hasil uji berat sampel pada kedua kondisi menunjukkan keseragaman berat rata - rata yakni berkisar 7,10 - 7,25 gram dengan standar deviasi 0,02 - 0,05 gram. Hasil uji juga menunjukkan bahwa berat sampel selama waktu penyimpanan dibandingkan dengan berat awal menunjukkan penurunan berat yang kecil yakni sekitar $0,1-0,2 \%$. Hal ini menunjukkan bahwa selama penyimpanan sediaan mempunyai stabilitas konsintensi berat yang baik.

Secara umum stabilitas fisika sediaan luka bakar menunjukkan stabilitas yang baik selama penyimpanan pada kedua kondisi pengamatan, kecuali untuk parameter warna dan bau yang sedikit kurang stabil. Hal ini terutama diakibatkan oleh warna yang dihasilkan adalah warna dari ekstrak pegagan itu sendiri dan penggunaan pewangi jenis alami yang digunakan. Hasil pengujian $\mathrm{pH}$ sediaan lukabakar selama proses penyimpanan pada suhu kamar dan suhu dipercepat ditunjukkan pada Gambar 2. Sediaan menunjukkan pHyang cukup stabil yakni diantara 3,75 - 4,25 dengan standar deviasi 0,05 - 0,15 dan sifat asam sediaan ini terutama diakibatkan oleh adanya asam laktat sebagai bahan yang digunakan untuk melarutkan kitosan.

Parameter stabilitas kimia yang diamati lainnya adalah profil kromatogram dari sediaan luka bakar. Gambar 3 A - C dan Gambar 4 A - B menunjukkan profil kromatogram sediaan luka bakar pada dua kondisi pengamatan setelah waktu penyimpanan yang berbeda.

Kromatogram menunjukkan pola yang sama antara senyawa standar dengan sampel sediaan yakni adanya puncak senyawa asiaticoside yang dijadikan sebagai senyawa penanda untuk ekstrak pegagan. Waktu retensi antara puncak senyawa asiaticoside standar dengan puncak penanda senyawa asiaticoside pada sampel sediaan yakni masing - masing dapatdiamati pada waktu retensi 16 - 17 . Konsentrasi senyawa marker yang rendah pada sediaan luka bakar yang dianalisa menyebabkan puncak kromatogram senyawa tersebut tidak bisa diamati dengan jelas dan hal ini juga disebabkan karena dalam sediaan ada gangguan dari matrik bahan pengisi sediaaan yakni metolose.

Gangguan bahan metolose yang utama adalah disebabkan oleh konsentrasinya yang tinggi dalam sediaan, sehingga area puncaknya sangat tinggi dan menyebabkan puncak senyawa marker kurang terlihat jelas. Selain itu metolose mempunyai sifat kelarutan yang mirip dengan asiaticoside, sehingga saat proses ekstraksi/pemekatan senyawa marker bahan metolose akan ikut terekstraksi. Hal ini ditunjukkan adanya puncak metolose yang sangat dominan pada waktu retensi 11 menit pada sediaan, sedangkan pada senyawa standar tidak ada gangguan matrik lain.

Tabel 2. Hasil pengujian organoleptik sediaan luka bakar setelah penyimpanan 24 minggu pada suhu kamar 
JKTI, Vol. 17, No. 1, Juni $2015: 27-37$

\begin{tabular}{|c|c|c|c|c|c|c|c|c|c|c|c|}
\hline \multirow{2}{*}{ Sampel } & \multirow{2}{*}{ Parameter } & \multicolumn{10}{|c|}{ Minggu ke- } \\
\hline & & 0 & 2 & 4 & 6 & 8 & 10 & 12 & 16 & 20 & 24 \\
\hline \multirow{5}{*}{$\mathrm{F} 1$} & Bentuk & GT & GT & GT & GT & GT & GT & GT & GTC & GTC & GTC \\
\hline & Warna & $\mathrm{KMH}$ & $\mathrm{KMH}$ & $\mathrm{KMH}$ & $\mathrm{KMH}$ & $\mathrm{KMH}$ & $\mathrm{CMH}$ & $\mathrm{CMH}$ & $\mathrm{KC}$ & $\mathrm{KC}$ & $\mathrm{KC}$ \\
\hline & $\mathrm{Bau}$ & $\mathrm{H}(+5)$ & $\mathrm{H}(+5)$ & $\mathrm{H}(+5)$ & $\mathrm{H}(+5)$ & $\mathrm{H}(+5)$ & $\mathrm{H}(+5)$ & $\mathrm{H}(+5)$ & $\mathrm{H}(+3)$ & $\mathrm{H}(+3)$ & $\mathrm{H}(+3)$ \\
\hline & Homo & Homo & Homo & Homo & Homo & Homo & Homo & Homo & Homo & Homo & Homo \\
\hline & genitas & gen & gen & gen & gen & gen & gen & gen & gen & gen & gen \\
\hline
\end{tabular}

Tabel 3. Hasil pengujian organoleptik sediaan luka bakar setelah penyimpanan 12 minggu pada suhu dipercepat

\begin{tabular}{|c|c|c|c|c|c|c|c|c|}
\hline \multirow{2}{*}{ Sampel } & \multirow{2}{*}{ Parameter } & \multicolumn{7}{|c|}{ Minggu ke- } \\
\hline & & $\mathbf{0}$ & 2 & 4 & 6 & 8 & 10 & 12 \\
\hline \multirow{4}{*}{$\mathrm{F} 1$} & Bentuk & GT & GT & GT & GT & GT & GT & GT \\
\hline & Warna & $\mathrm{KMH}$ & $\mathrm{KMH}$ & KMH & $\mathrm{KMH}$ & HK & HK & $\mathrm{CM}$ \\
\hline & $\mathrm{Bau}$ & $\mathrm{H}(+5)$ & $\mathrm{H}(+5)$ & $\mathrm{H}(+5)$ & $\mathrm{H}(+4)$ & $\mathrm{H}(+4)$ & $\mathrm{H}(+3)$ & $\mathrm{H}(+3)$ \\
\hline & Homogenitas & Homogen & Homogen & Homogen & Homogen & Homogen & Homogen & Homogen \\
\hline
\end{tabular}

Keterangan :

$\begin{array}{lllll}G T & : \text { Gel transparan } & H K & : \text { Hijau kecoklatan } & \text { KT: Kuning tua } \\ \text { GTC } & : \text { Gel transparan lebih encer } & C M & : \text { Coklat muda } & \text { KC: Kuning coklat } \\ \text { KMH } & : \text { Kuning muda kehijauan } & F 1 & : \text { Kode formula } & \\ \text { CMH } & : \text { Coklat muda kehijauan } & H & : \text { Harum }\end{array}$

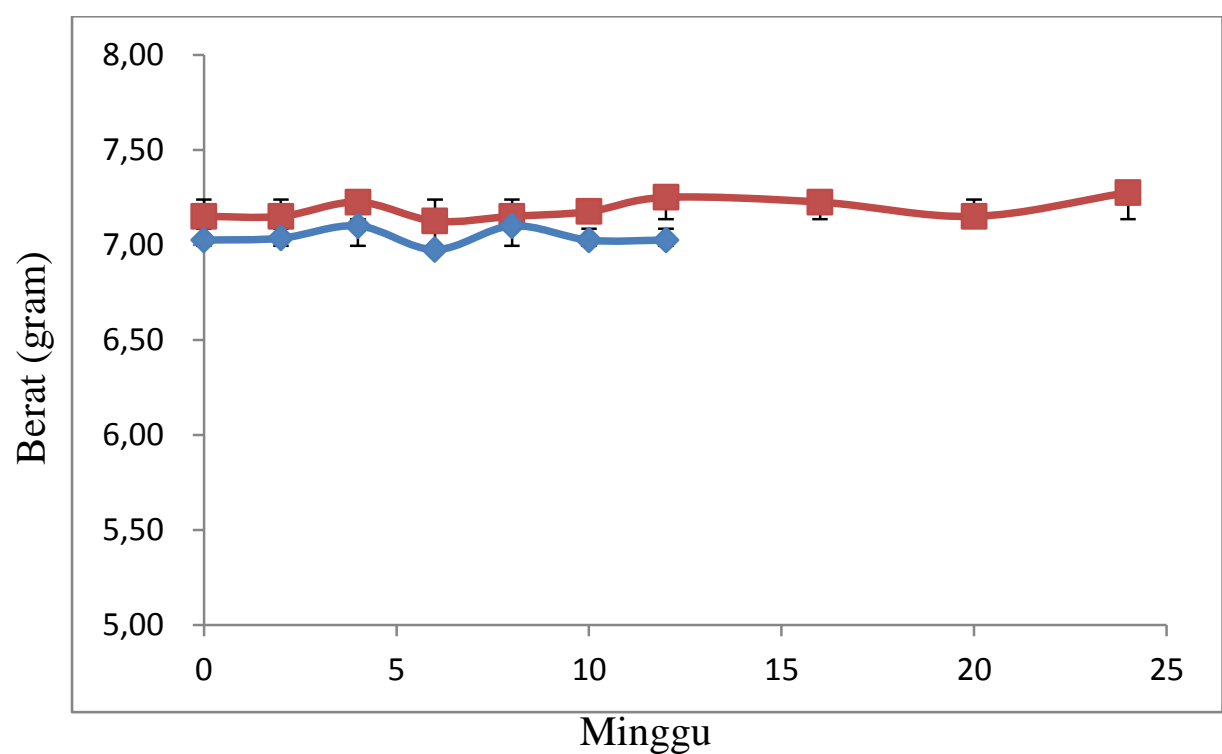

Gambar 1. Berat sediaan pada pengujian suhu kamar selama 24 minggu (garis coklat) dan suhu dipercepat selama 12 minggu (garis biru) 


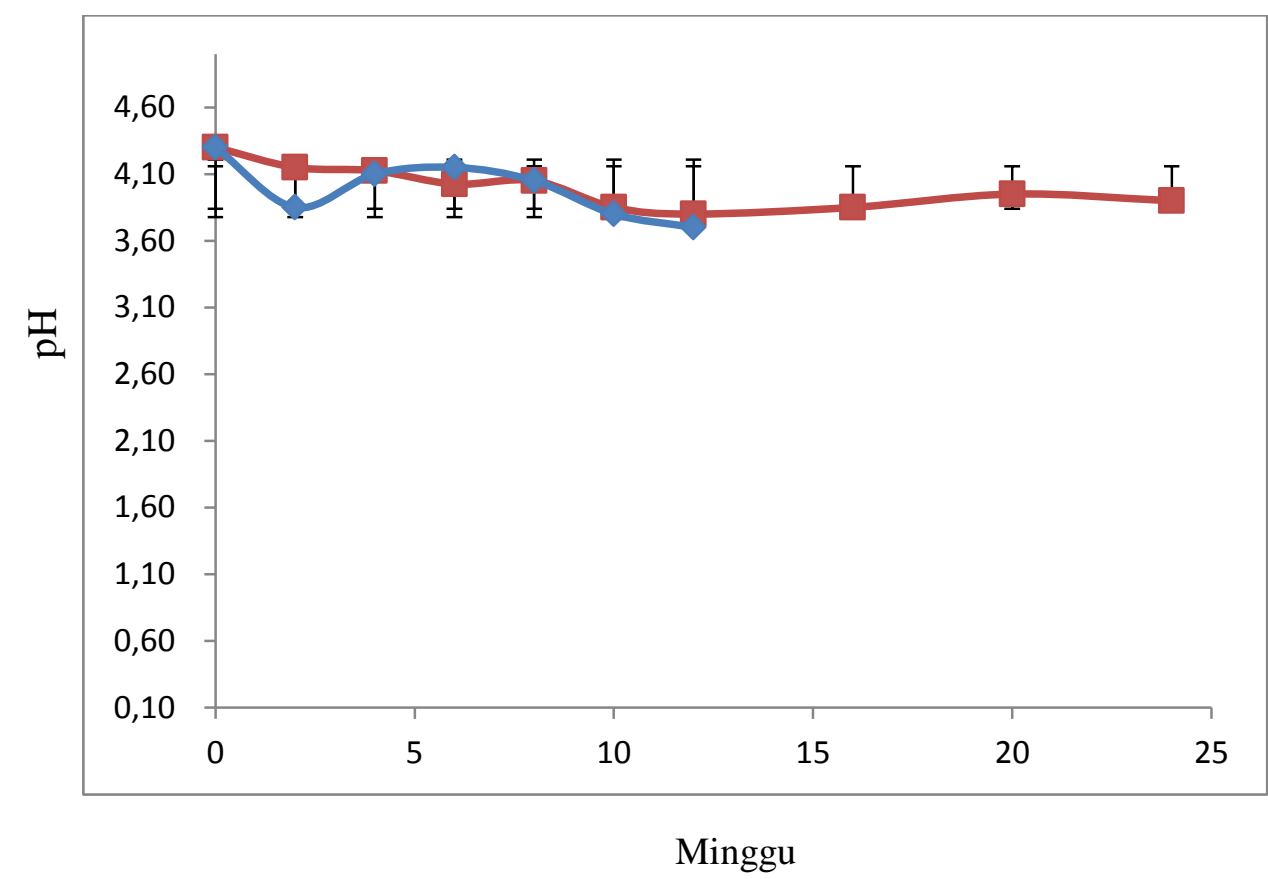

Gambar 2. Stabilitas pH sediaan pada suhu kamar selama 24 minggu (garis coklat) dan suhu dipercepat selama 12 minggu (garis biru)
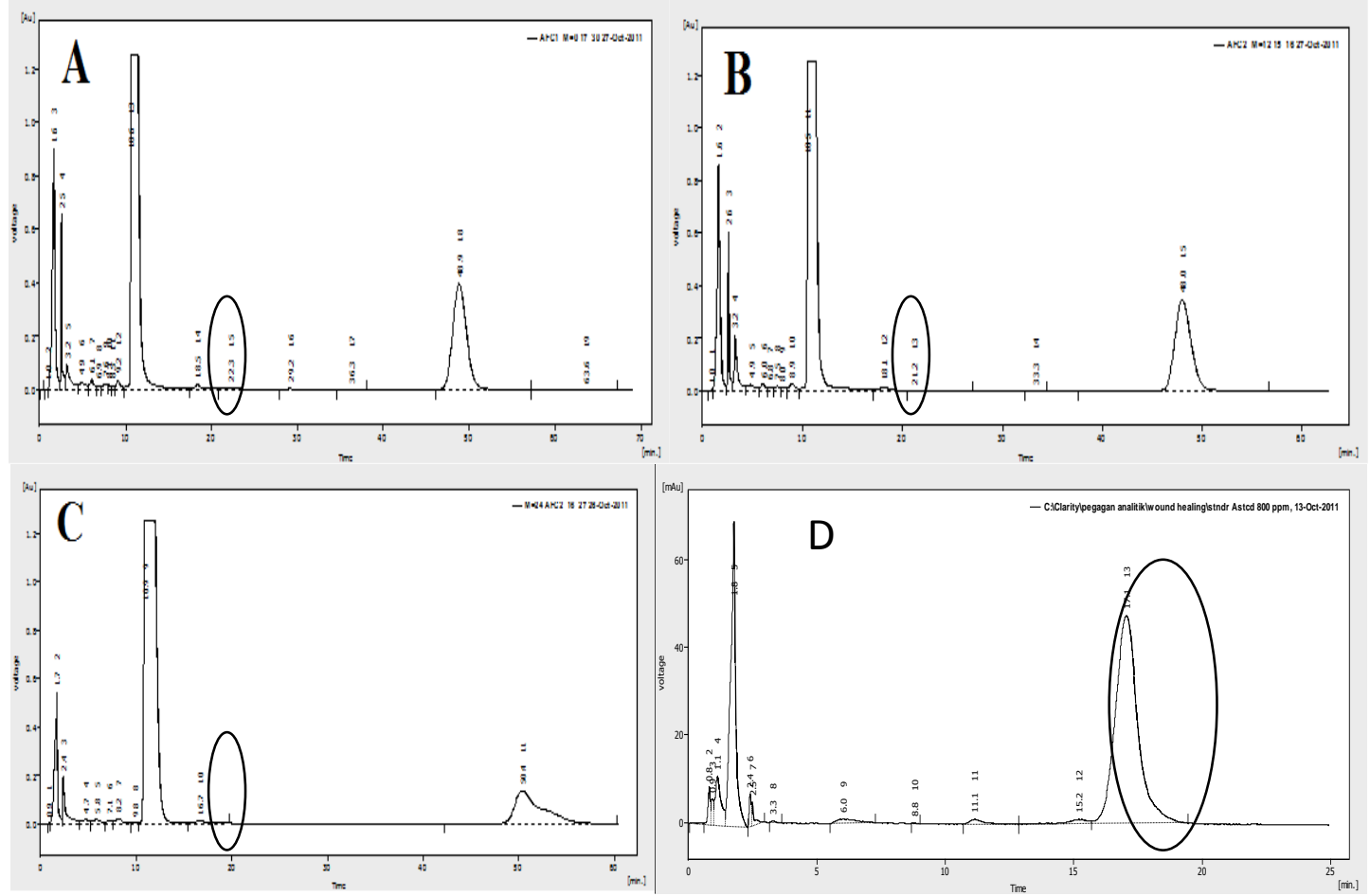

Gambar 3. Profil kromatografi KCKT sediaan pada penyimpanan suhu kamar pada minggu : a) ke-0, b) ke-12, c) ke-24 dan d) standar asiaticoside $600 \mathrm{ppm}$ 

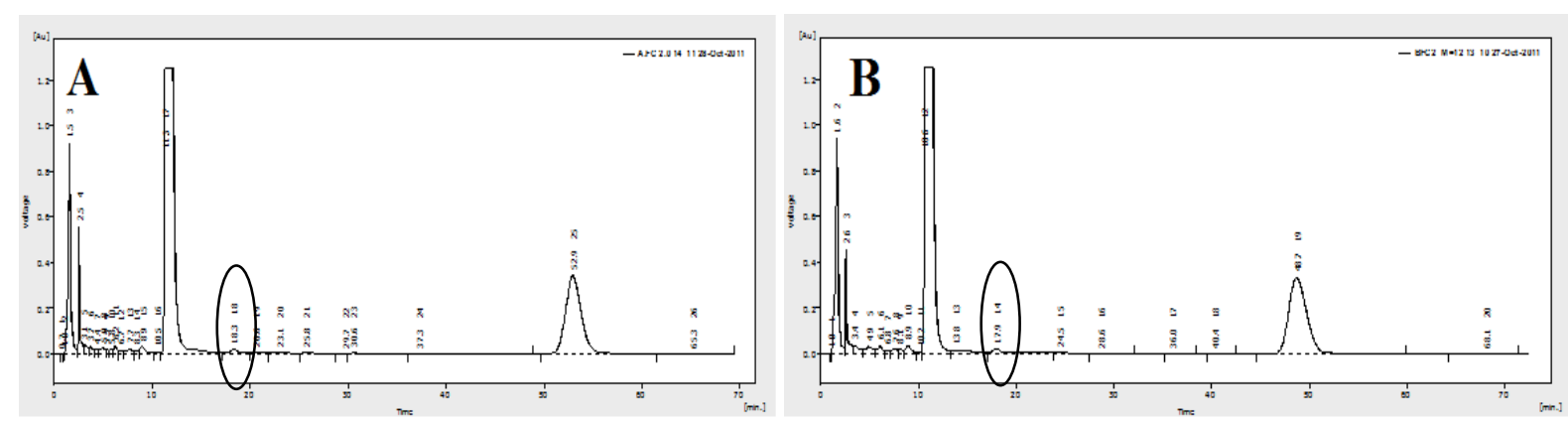

Gambar 4. Profil kromatografi KCKT sediaan pada penyimpanan suhudipercepatpada minggu : a) ke-0, dan b) ke- 12

Untuk membuktikan bahwa puncak pada waktu retensi $16-17$ adalah asiaticoside yang ada dalam sampel sediaan, maka sudah dilakukan pengujian secara internal standar dengan menambahkan sejumlah larutan asiaticoside standar pada larutan sampel. Hasil uji menunjukkan bahwa pada waktu retensi yang sama dapat diamati bahwa luas area puncak mengalami perubahan sesuai naiknya konsentrasi yang ditambahkan dan ini menunjukkan bahwa puncak tersebut adalah asiaticoside. Dengan dapat diamatinya puncak senyawa asiaticoside selama waktu pengujian pada kedua kondisi menunjukkan bahwa senyawa kimia yang ada dalam sediaan adalah cukup stabil. Hasil pengujian kuantitatif menunjukkan bahwa kadar asiaticoside dalam sediaan yang dihitung terhadap kurva standar (Gambar 5) berdasarkan data pada Tabel 4 selama waktu penyimpanan pada suhu kamar dan suhu dipercepat adalah cukup stabil yakni berkisar $50-65$ ppm. Secara umum stabilitas kimia sediaan luka bakar menunjukkan stabilitas yang baik selama penyimpanan pada kedua kondisi pengamatan.

Tabel 4. Data hasil pengujian KCKT untuk kurva kalibrasi, sampel minggu 0,minggu ke 12 dan minggu ke 24

\begin{tabular}{|c|c|c|c|}
\hline Larutan Uji & $\begin{array}{l}\text { Luas } \\
\text { area }\end{array}$ & $\begin{array}{c}\text { Kadar dari } \\
\text { kurva kalibrasi } \\
\text { (ppm) }\end{array}$ & $\begin{array}{c}\text { Kadar dalam } \\
\text { sediaan } \\
\text { (ppm) }\end{array}$ \\
\hline Standar asiaticoside $350 \mathrm{ppm}$ & 764,13 & - & - \\
\hline Standar asiaticoside $400 \mathrm{ppm}$ & 1268,05 & - & - \\
\hline Standar asiaticoside 600 ppm & 1843,28 & - & - \\
\hline Standar asiaticoside $800 \mathrm{ppm}$ & 2271,93 & - & - \\
\hline Standarasiaticoside 1000 ppm & 2934,79 & - & - \\
\hline Sampel minggu ke 0 & 693,13 & 262,63 & 65,65 \\
\hline Sampel minggu ke 12 suhu dipercepat & 648,09 & 247,90 & 61,97 \\
\hline Sampel minggu ke 12 suhu kamar & 649,35 & 248,31 & 62,07 \\
\hline Sampel minggu ke 24 suhu kamar & 499,06 & 199,16 & 49,79 \\
\hline
\end{tabular}




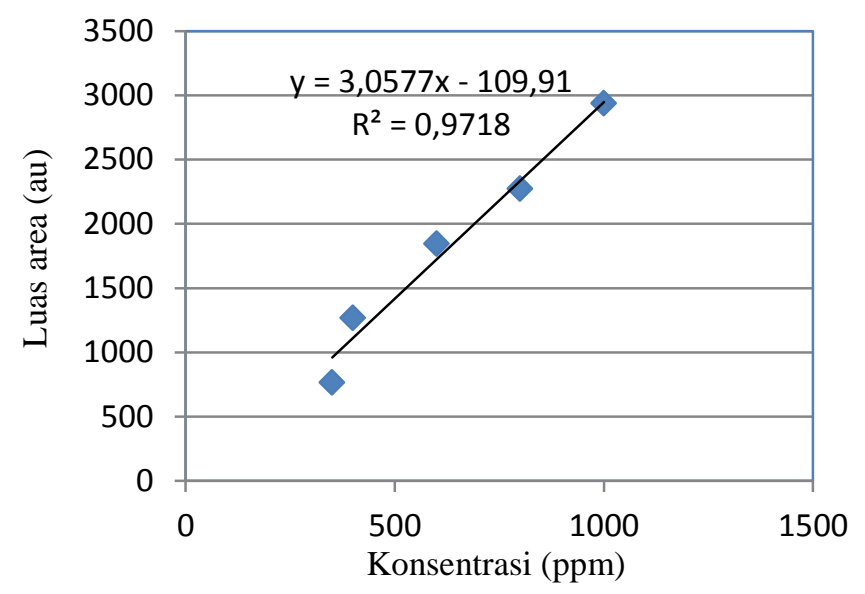

Gambar 5. Kurva kalibrasi asiaticoside hasil analisis KCKT

Hasil uji stabilitas mikrobiologi sediaan luka bakar selama penyimpanan pada suhu kamar selama 24 minggu dan penyimpanan suhu $40^{\circ} \mathrm{C}$ RH $75 \%$ selama 12 minggu ditunjukkan pada Tabel 5 dan 6. Hasil uji stabilitas mikrobiologi menunjukkan bahwa angka lempeng total (ALT) dan angka kapang kamir (AKK) pada sediaan tersebut selama penyimpanan masih memenuhi persyaratan yakni berada di bawah persyaratan untuk angka lempeng total sediaan $=<10$ dan angka kapang khamir $<10$. Dengan kata lain formula sediaan lukabakar tersebut mempunyai stabilitas mikrobiologi yang baik dan aman untuk digunakan secara topikal.

Tabel 5. Hasil uji angka lempeng total dan kapang khamir pada sediaan selama penyimpanan 24 minggu pada suhu kamar

\begin{tabular}{ccccccccccccc}
\hline \multirow{2}{*}{ Sampel } & Parameter & \multicolumn{10}{c}{ Minggu ke- } \\
\cline { 3 - 12 } & & $\mathbf{0}$ & $\mathbf{2}$ & $\mathbf{4}$ & $\mathbf{6}$ & $\mathbf{8}$ & $\mathbf{1 0}$ & $\mathbf{1 2}$ & $\mathbf{1 6}$ & $\mathbf{2 0}$ & $\mathbf{2 4}$ \\
\hline \multirow{2}{*}{ F1 } & ALT & $<10$ & $<10$ & $<10$ & $<10$ & $<10$ & $<10$ & $<10$ & $<10$ & $<10$ & $<10$ \\
& AKK & $<10$ & $<10$ & $<10$ & $<10$ & $<10$ & $<10$ & $<100$ & $<10$ & $<10$ & $<10$ \\
\multirow{3}{*}{ Blanko } & ALT & $<10$ & $<10$ & $<10$ & $<10$ & $<10$ & $<10$ & $<10$ & $<10$ & $<10$ & $<10$ \\
& AKK & $<10$ & $<10$ & $<10$ & $<10$ & $<10$ & $<10$ & $<100$ & $<10$ & $<10$ & $<10$ \\
\hline
\end{tabular}

Tabel 6. Hasil uji angka lempeng total dan kapang khamir pada sediaan selama penyimpanan 12 minggu pada suhu dipercepat

\begin{tabular}{cccccccccc}
\hline \multirow{2}{*}{ Sampel } & Parameter & \multicolumn{1}{c}{ Minggu ke- } & & \\
\cline { 3 - 9 } & & $\mathbf{0}$ & $\mathbf{2}$ & $\mathbf{4}$ & $\mathbf{6}$ & $\mathbf{8}$ & $\mathbf{1 0}$ & $\mathbf{1 2}$ \\
\hline \multirow{2}{*}{ F1 } & ALT & $<10$ & $<10$ & $<10$ & $<10$ & $<10$ & $<10$ & $<100$ \\
& AKK & $<10$ & $<10$ & $<10$ & $<10$ & $<10$ & $<10$ & $<100$ \\
\multirow{3}{*}{ Blanko } & ALT & $<10$ & $<10$ & $<10$ & $<10$ & $<10$ & $<10$ & $<10$ \\
& AKK & $<10$ & $<10$ & $<10$ & $<10$ & $<10$ & $<10$ & $<10$ \\
\hline
\end{tabular}


Secara umum dengan merujuk pada PerKaBPOM terkait maka sediaan luka bakar telah memenuhi persyaratan stabilitas terhadap parameter - parameter yang ditentukan.

\section{KESIMPULAN}

Formula sediaan gel woundhealingdengan bahan aktif kitosan dan ekstrak pegagan menunjukkan stabilitas fisik, kimia dan mikrobiologi yang cukup baik selamapenyimpanan pada suhu kamar selama enam bulan dan penyimpanan suhu $40{ }^{\circ} \mathrm{C}$ RH $75 \%$ selama tiga bulan. Dua parameter fisika yakni warna dan bau menunjukkan sedikit penurunan stabilitas ditunjukkan oleh adanya perubahan warna dan berkurangnya intensitas bau harum.

\section{DAFTAR PUSTAKA}

1. Departemen Kesehatan Republik Indonesia. Farmakope Indonesia. Edisi IV. Jakarta. 847 - 854, 999, 1037-9. 2005

2. Departemen Kesehatan Republik Indonesia. Farmakope Herbal Indonesia, Edisi I, 2013

3. BPOM - Departemen Kesehatan Republik Indonesia. Peraturan KBPOM No 44 Tahun 2013 Perubahan Atas Peraturan Kepala Badan Pengawas Obat dan Makanan Nomor Hk.03.1.23.12.10.12459 Tahun 2010 Tentang Persyaratan Teknis Kosmetika

4. BPOM - Departemen Kesehatan Republik Indonesia. Peraturan KBPOM No 17 Tahun 2014. Perubahan Atas Peraturan Kepala Badan Pengawas Obat dan Makanan Nomor Hk.03.1.23.07.11.6662 Tahun 2011 Tentang Persyaratan Cemaran Mikroba Dan Logam Berat Dalam Kosmetika

5. A. Martin, J. Swarbrick, A. Cammarata. Farmasi Fisik: Dasar-Dasar Farmasi Fisik dalam Ilmu Farmasetika. Edisi
Ketiga. Jakarta. UI-Press : Jilid 2. 11431164. 2008

6. L. Lachman, H.A. Lieberman, J.L. Kanig. Teori dan Praktek Farmasi Industri II. Diterjemahkan oleh Siti Suyatmi. Penerbit Universitas Indonesia. Edisi ke-3. 1029-1089. 1994

7. Wikipedia-Centella asiatica. Situs resmi. Tersedia pada: http://en.wikipedia.org/wiki/Centella_as iatica. [Diakses tanggal 1 Oktober 2009].

8. S. P. Jong et al. Asiaticoside mimetic as wound healing agent. Biorganic \& Medical Chemistry Letters. Volume 6. No.24. 2937-2940 (1996)

9. K. Yoshiyuki et al. Facilitating action of asiaticoside at low doses on burn wound repair and its mechanism. European Journal of Pharmacology. 584. 415423 ( 2008)

10. R. Vishnu et al. Influence Of Aqueous Extract Of Centella As/At/Ca (Brahmi) On Experimental Wounds In Albino Rats. Indian Journal of Pharmacology. 28: 249-253 (1996)

A. Shukla et al. In Vitro and in Vivo Wound Healing Activity of Asiaticoside Isolated from Centella asiatica. Journal of Ethnopharmacology. 65:1-11(1999)

11. M.N. Somchit et al. Antinociceptive and antiinflammatory effects of Centella Asiatica. Indian Journal Pharmacol. Vol 36. Issue $6: 377-380$. (2004).

12. Committee for Veterinary Medicinal Product Centellla asiatica extract. Summary Report. The European Agency For The Evaluation of Medicinal Products Veterinary Medicines Evaluation Unit. EMEA/MRL/494/98- FINAL. 1998.

13. Q.L. Yu, H.Q Duan, Y. Takaishi, W.Y. Gao. A Novel Triterpene from Centella asiatica. Molecules, 11: 661-665 (2006)

14. National Agency of Drug and Food Control The Republic of Indonesia Monography of Indonesian Medicinal Plant Extract. 2004. 
15.P. Sikareepaisan et al. Electrospun gelatin fiber mats containing a herbalCentella asiatica-extract and release characteristic of asiaticoside. Nanotechnology. 19 :95- 102. (2008)

16. S.A. Agnihotri, N. Nadagounda, Mallikarjuna, M. Tejraj, Aminabhavi. Recent advances on chitosan-based micro- and nanoparticles in drug delivery. J. Control. Release. 100 : 5-28 (2004)

17. E. Rismana, I. Rosidah, O. Bunga, P. Yunianto, Erna . Efektivitas khasiat wound healing sediaan gel mengandung fraksi ekstrak pegagan berdasarkan analisis hidroksiprolin dan histopatologi pada kulit kelinci. Buletin Penelitian Kesehatan. Volume 41. No 1. Maret (2013)

18. BPOM - Departemen Kesehatan Republik Indonesia. PerKaBPOM No 12 Tahun 2014 tentang Persyaratan Mutu Obat Tradisional.

19. E. Rismana, S.Kusumaningrum, I. Rosidah, Nizar, Marhamah. Pengujian Stabilitas Sediaan Antiacne Dengan Bahan Aktif Kitosan/Ekstrak ManggisPegagan. Buletin Penelitian Kesehatan. Desember 41 (4). 207 -216 (2013).

20. E.S. Kuncari, Iskandarsyah, Praptiwi. Evaluasi, Uji Stabilitas Fisik dan Sineresis Sediaan Gel Yang Mengandung Minoksidil, Apigenin dan Perasan Herba Seledri (Apium graveolens. L.). Buletin Penelitian Kesehatan. Desember. 42 (4). 213-222 (2014)

21. M.H. Rafamantanan et al. An improved HPLC-UV method for the simultaneous quantification of triterpenic glycosides and aglycones in leaves of Centella asiatica (L.) Urb (APIACEAE). Journal of Chromatography B. 877. 2396-2402. (2009) 
JKTI, Vol. 17, No. 1, Juni 2015 